Case Report

\title{
A mandibular second premolar with three canals and atypical orifices
}

\author{
Mehrdad Lotfi ${ }^{1)}$, Sepideh Vosoughhosseini ${ }^{2)}$, Vahid Zand ${ }^{3)}$, Ali Fatemi ${ }^{3)}$, \\ Vahab Shyezadeh ${ }^{3)}$ and Bahram Ranjkesh ${ }^{4}$ \\ ${ }^{1)}$ Department of Endodontics, Dental School and Research Center for Pharmaceutical Nanotechnology, \\ Tabriz University (Medical Sciences), Tabriz, Iran \\ ${ }^{2}$ Department of Oral and Maxillofacial Pathology, Dental School and Research Center for Pharmaceutical \\ Nanotechnology, Tabriz University (Medical Sciences), Tabriz, Iran \\ ${ }^{3)}$ Department of Endodontics, Dental School, Tabriz University (Medical Sciences), Tabriz, Iran \\ ${ }^{4)}$ Private practice, Tabriz, Iran
}

(Received 26 November 2007 and accepted 7 July 2008)

\begin{abstract}
Mandibular second premolars with three canals (Type V, Vertucci) and separate foramina are very rare. The anatomy of the pulp chamber floor in these premolars usually reveals one lingual and two buccal orifices at the same level. This case report describes a second premolar with three canals and an unusual pulpal floor anatomy with one distobuccal and one distolingual orifice at the same level and an orifice on the mesiolingual wall. Very careful examination of the pulpal space, preferably with an optical device, is recommended to locate any unusual orifices. (J. Oral Sci. 50, 363-366, 2008)
\end{abstract}

Keywords: three canal mandibular second premolar; premolar with three foramina.

\section{Introduction}

Sound knowledge of the root canal morphology and pulp chamber anatomy is a prerequisite for successful root canal treatment. The prevalence of three root canals with three distinct orifices that end in separate foramina was reported to be $0.4 \%$ by Zillich and Dowson in 1973 (1)

Correspondence to Dr. Sepideh Vosoughhosseini, Department of Oral and Maxillofacial Surgery, Dental School, Tabriz University (Medical Sciences), Golgasht Street, Tabriz, Azarbaidjan Sharghi 5166614711, Iran

Tel: +98-411-3337801

Fax: +98-411-3366977

E-mail: mehrlotfi@yahoo.com and El Deeb in 1982 (2). Cases of mandibular second premolars with three canals have been described by many investigators (3-11). All these cases, except for one, observed three orifices on the floor of the pulp chamber, one of which was located in the lingual and the other two in the buccal part of the pulp chamber (mesiobuccal and distobuccal).

De Moor et al (10) were the only ones who reported the atypical occurrence of three canals in the second premolar, with two orifices in the distal half of the furcation area and one orifice on the mesial wall of the pulp chamber.

The purpose of this article was to describe a mandibular second premolar with three canals having three independent and atypical orifice openings in the pulp chamber.

\section{Case Report}

A 21-year-old Iranian female with noncontributory medical history was referred to the Endodontics Department of Tabriz Dental School for endodontic treatment of the left mandibular second premolar by her dentist. The patient complained of "pain and swelling in the lower left teeth." Clinical examination revealed two intact teeth (third molar and first premolar). There was a large amalgam restoration on the first molar and a dressing in the distal part of the second premolar. A localized swelling was seen in the region between the first and second premolars. The second premolar was tender to horizontal and vertical percussion and vitality test showed no response to cold and heat and EPT. Radiographic examination demonstrated normal periodontal ligament widening in the first and second 
premolars. A periapical radiolucency of size $4 \times 4 \mathrm{~mm}$ was observed in the mesial root of the first molar associated with improper root canal treatment (Fig. 1). A diagnosis of necrotic pulp and acute periradicular periodontitis was made for the second premolar. Two-visit nonsurgical endodontic treatment was planned with calcium hydroxide as intra-canal medicament between two appointments. An inferior alveolar nerve block was established with 1.8 $\mathrm{ml}$ of $2 \%$ Lidocaine $\mathrm{HCl}$ and 1:100,000 epinephrine. Under rubber dam isolation, the dressing was removed and access cavity modified. One main canal orifice was found which split into two independent canal orifices in the mid root level (mesiolingual and distolingual) (Fig. 2). In order to carefully inspect the pulp chamber space, Gates-Glidden drills (Maillefer, Ballaigues, Switzerland) 5, 4 and 3 set

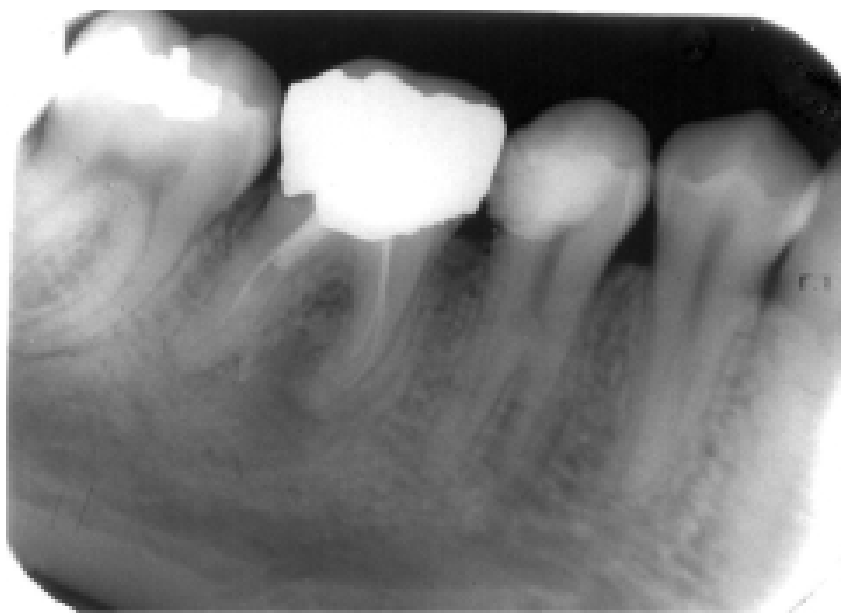

Fig. 1 Lower left second premolar with three separate roots.

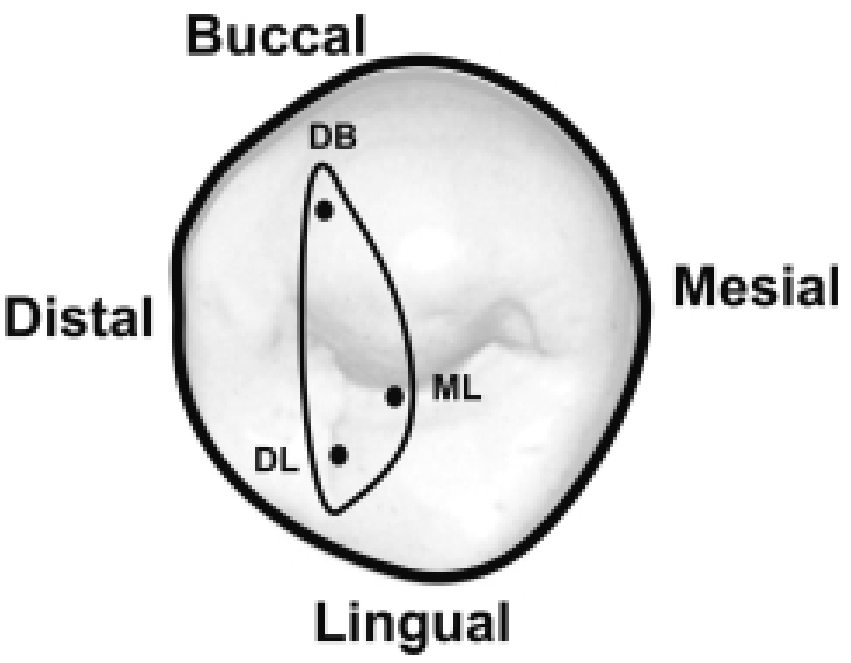

Fig. 2 Schematic location of three orifices in the mandibular second premolar pulp chamber. on a slow hand piece rotating at 1,000 rpm with brushing motion under copious irrigation with $2.5 \%$ sodium hypochlorite were used to enlarge the main orifice to the level of the furcation.

The pulp chamber was located in the distal half of the tooth. Careful inspection of the pulpal floor and walls revealed a black spot in the mesiolingual wall that could be negotiated with a $0.08 \mathrm{~K}$ file (Maillefere) (Figs. 3 and 4). Working lengths were determined by an Apex locator (Denta port ZX, J. Morita Inc.) and confirmed by radiograph (Fig 4). All canals were instrumented up to $25 \mathrm{~K}$-Flexofile (Maillefere) with RC Prep (Premier, Norristown, PA,

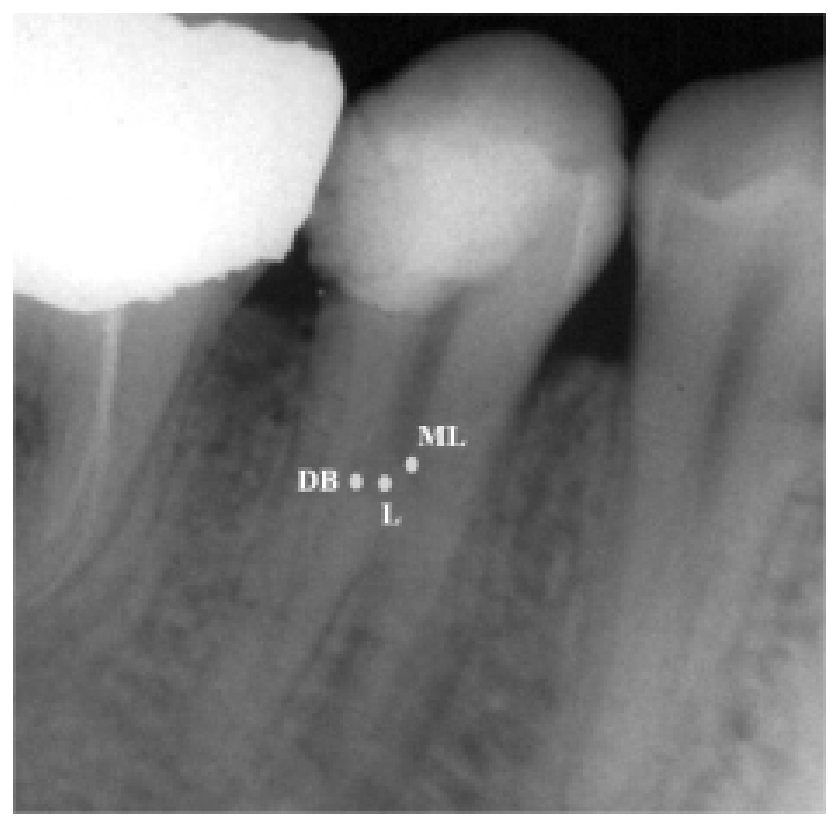

Fig. 3 Atypical orifices in the mandibular second premolar.

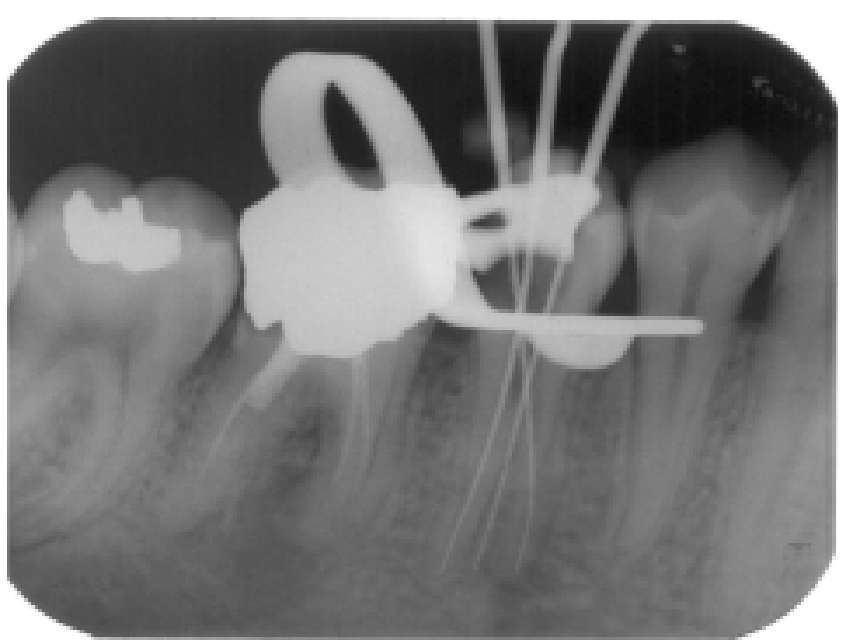

Fig. 4 Working length determination in the mandibular left second premolar. 
USA) under copious irrigation with $2.5 \%$ sodium hypochlorite during instrumentation. Calcium hydroxide (Calasept, Nordiska, Angelholm, Sweden) was used as the intra-canal dressing and the access cavity was sealed with IRM (Dentsply, De Tray, Konstanz, Germany).

After two weeks, clinical examination revealed that all symptoms had subsided. The IRM was removed and the tooth isolated. Calcium hydroxide was removed with a 25 $\mathrm{K}$ file under copious irrigation with $2.5 \%$ sodium hypochlorite. After drying the canals with paper point, obturation was performed with gutta percha and AH 26 sealer (De Trey, Dentsply, Konstanz, Germany) using the lateral condensation method. A radiograph was taken to assess the quality of obturation (Fig. 5).

\section{Discussion}

The morphology of the root and canals of the mandibular second premolar can be complex and variable (12). Because of the varied morphology, endodontic treatment in second mandibular premolar is a challenging task. Therefore, the internal morphology must be identified precisely to achieve successful treatment. The anatomical landmark of the pulp chamber floor may help to identify supplementary root canals or root canal aberrations (10).

Many authors who located orifices in the pulp chamber of the lower second premolar reported one orifice in the lingual side and two in the buccal $(7,9,11)$. One case had three atypical orifices, of which two merged in the distal half of the furcation area while the other opened on the mesial wall of the pulp chamber (10). In this case, we encountered the same situation, and another unusual orifice was observed. Pulpal floor anatomy demonstrated one

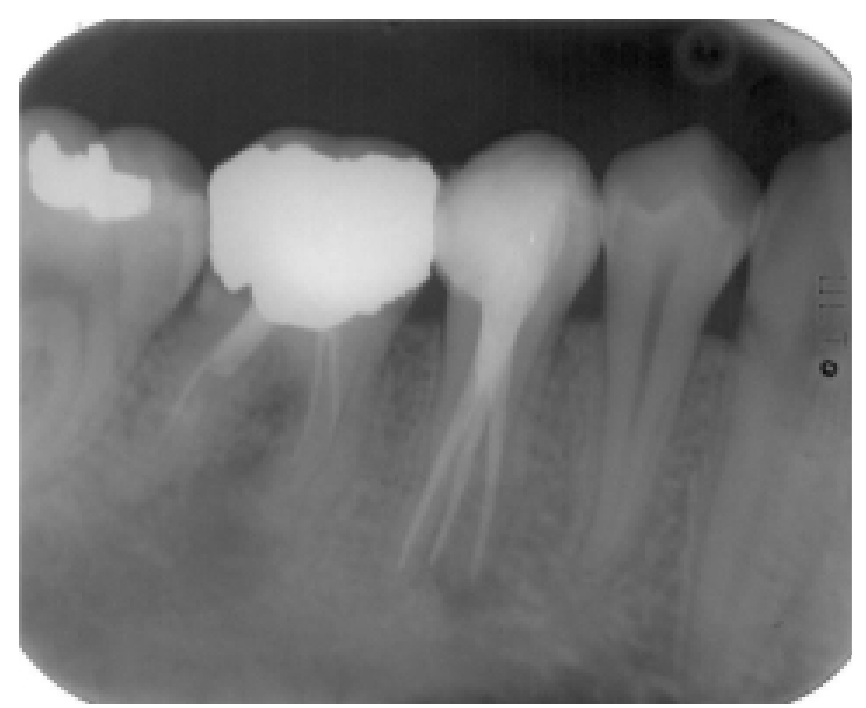

Fig. 5 Radiographic image of the second premolar after obturation. distobuccal and one distolingual orifice at the same level and one orifice on the mesiolingual wall.

The root shape, root position and relative root outline should be carefully determined from the radiograph. Good quality preoperative radiographs and thorough radiographic examination are essential for the detection of additional root canals $(6,13,14)$. Sudden narrowing or a disappearing pulp space may indicate the presence of another canal or canals (15). In the present case, the radiographic features suggested the possibility of three canals. However, because of the superimposition of roots, radiographic diagnosis of three canals is not always possible in all cases. Several clinical indications may be useful in the detection of a third canal in mandibular second premolars. In some situations, a third canal may exist clinically when the pulp chamber does not appear to be aligned in its usual buccolingual relationship. Furthermore, if the pulp chamber appears to deviate from normal configuration and seems to be either triangular in shape or overly large in the mesiodistal direction, more than one canal should be suspected. It appears difficult to establish a rule to locate the orifice in second lower premolars, and further studies should be done before establishing these guidelines. According to another case report (10), detecting orifices, especially of the third canal, is a great challenge for the dentist. Many practitioners recommended using Gates-Glidden drills to open the main canal for better visualization. In the present case, we used Gate-Glidden drills to improve visualization; only after using GG was the third orifice found. Tactile examination of all the walls of the major canal with a small, precurved k-file tip is recommended, in order to probe for a catch which may indicate the orifice of an additional canal. However, using this technique without any previous idea about the location of the orifices may be time consuming and frustrating.

The use of dyes, especially methylene blue, was reported to be helpful in finding orifices (16). However, De Moor and Calberson (10) did not find methylene blue helpful. In that case report, the third canal orifice was covered by a dentin protuberance. Therefore, even if methylene blue could penetrate into the orifice, the protuberance might hide the orifice from direct visualization.

Microscopes are commonly used to explore the pulp chamber in order to find orifices.

The advantages of using a microscope for conventional endodontics include better visualization of the pulp chamber floor and walls that prevents inadvertent missing of orifices. Although we did not use a microscope, we recommend it for better visualization. It is assumed that careful observation and inspection of the pulpal floor and also pulpal wall is mandatory to avoid the unexpected missing 
of orifices that may cause unsuccessful endodontic treatment. Attention to the color changes on the pulpal floor and wall during inspection instead of searching for defined places might be helpful to locate orifices. In this patient, a black spot led us to find the third orifice.

\section{References}

1. Zillich R, Dowson J (1973) Root canal morphology of mandibular first and second premolars. Oral Surg Oral Med Oral Pathol 36, 738-744

2. ElDeeb ME (1982) Three root canals in mandibular second premolars: literature review and a case report. J Endod 8, 376-377

3. Kaffe I, Kaufman AY, Littner MM (1985) Diagnosis of premolars with multiple canals using radiography. Quintessenz 36, 1121-1126 (in German)

4. Singh RP, Stamps HF, Tatum RC (1987) Endodontic considerations of a tricanaled mandibular second premolar: case report and literature review. J Md State Dent Assoc 30, 13-16

5. Glassman GD (1987) Flare-up with associated paresthesia of a mandibular second premolar with three root canals. Oral Surg Oral Med Oral Pathol 64, 110-113

6. England MC Jr, Hartwell GR, Lance JR (1991) Detection and treatment of multiple canals in mandibular premolars. J Endod 17, 174-178
7. Chan K, Yew SC, Chao SY (1992) Mandibular premolar with three root canals - two case reports. Int Endod J 25, 261-264

8. Fischer GM, Evans CE (1992) A three-rooted mandibular second premolar. Gen Dent 40, 139-140

9. Rödig T, Hülsmann M (2003) Diagnosis and root canal treatment of a mandibular second premolar with three root canals. Int Endod J 36, 912-919

10. De Moor RJ, Calberson FL (2005) Root canal treatment in a mandibular second premolar with three root canals. J Endod 31, 310-313

11. Nallapati $S$ (2005) Three canal mandibular first and second premolars: a treatment approach. J Endod $31,474-476$

12. Ash MM Jr (2003) Wheeler's dental anatomy, physiology and occlusion. 8th ed, W. B. Saunders, Philadelphia, 151-156

13. Slowey RR (1979) Root canal anatomy. Road map to successful endodontics. Dent Clini North Am $23,555-573$

14. Hülsmann M (1990) Mandibular first premolar with three root canals. Endod Dent Traumatol 6, 189-191

15. Vertucci FJ (1978) Root canal morphology of mandibular premolars. J Am Dent Assoc 97, 47-50

16. Bahcall JK, Barss JT (2001) Fiberoptic endoscope usage for intracanal visualization. J Endod 27, 128129 